\title{
Optimization of Traffic Signalization Timings to Reduce Queue Length and Vehicle Delays: A Case Study in Çukurova University
}

\section{Gökhan Tüccar ${ }^{1 *}$, Erinç Uludamar²}

${ }^{1}$ Adana Science and Technology University, Turkey

\begin{abstract}
After each central exam organized by OSYM (Measuring, Selection and Placement Centre), traffic jam occurs since thousands of vehicles of candidates and instructors enter into a two lane way, which is the only road that combines the Çukurova University (ÇU) campus to city center, within a short period of time. In order to organize traffic flow and reduce queue lengths and vehicle delays occur in main roads, traffic signalization plays an important role. There are number of simulation tools used in order to understand traffic flow trend and minimize problems associated with vehicle concentration such as CMEM, VISSIM, SYNCHRO, TRANSYT-7F and VISGAOST. Among them VISSIM comes front which has the ability to simulate complex traffic flow and convert the field data into processable mathematical values. In this study, VISSIM program was used decide best signal timing in order to deal with traffic problem created by vehicle concentration after central exams.
\end{abstract}

Keywords: Optimization, traffic signalization, VISSIM, Vehicular emission

\section{INTRODUCTION}

Urban traffic problem is one of the most annoying problems generally occurs in developing and developed countries. Traffic intensity increases since highway capacities do not fulfil increasing number of new vehicles. Most important results of traffic intensity are increased environmental pollution because of emission gases resulted from excessive fuel consumption, loss of time, increase in driver stress and noise pollution as a result of long queues created in traffic [1].

Optimization of signal timing is a very efficient way to control traffic flow and reduce fuel consumption and exhaust emissions on urban streets[2]. Since 1950's a lot of effort have been consumed in order to understand traffic flow trend which represents traffic situation in developed countries [3-7]. Researches have showed that optimization of signal timings has improved both vehicular emissions and fuel consumption. Robertson et al. studied signal optimization in order to reduce delays and stops occur in city traffic [8]. Their study was one of the pioneers of researches introducing optimization of signal timings.

Stevanovic et. al studied signal timings at 14-intersection network in Park City, Utah. They tried to find the best signal timings for the lowest fuel consumption and $\mathrm{CO}_{2}$ emissions. Their model estimated fuel savings of about $1.5 \%$ with signal optimization. Dissanayake et. al. [9] also used genetic algorithm for optimization of signal timings and they conducted comparative experiments on various simulation software's under the same geometry and traffic conditions.

VISSIM is a microscopic time step and behaviour based simulation model. By using VISSIM, traffic can be modelled as well as flow of pedestrians. It can analyze public and private transport operations making it a useful tool for evaluation of various alternatives for transportation planning [10].

The aim of this study was to determine effect of signal timing on traffic concentration, queue length and vehicle emissions in a complicated intersection which combines Çukurova University to Adana town centre. VISSIM software was used in order to simulate traffic flow throughout the study.

\section{METHODOLOGY}

Number of vehicles in Çukurova University Campus increases dramatically after central exams, since nearly 3000 vehicle enter to a two lane road within half an hour. This road normally cannot overcome that kind of demand and long queues form periodically at the end of the road. As a result, it takes number of minutes to leave the campus.

\footnotetext{
*Corresponding authour

Email: gtuccar@adanabtu.edu.tr (G. Tüccar)

$\S$ This paper was presented in the IMSEC-2016
} 
At the end of the road a 5 road intersection is placed. The signalization period of this intersection directly affects the queue that is formed after exams. Therefore, special signalization timing is necessary after central exams to overcome the traffic jam which is the main aim of this study. The satellite image and screen shot of the model of the intersection is shown in Figures 1 and 2, respectively.

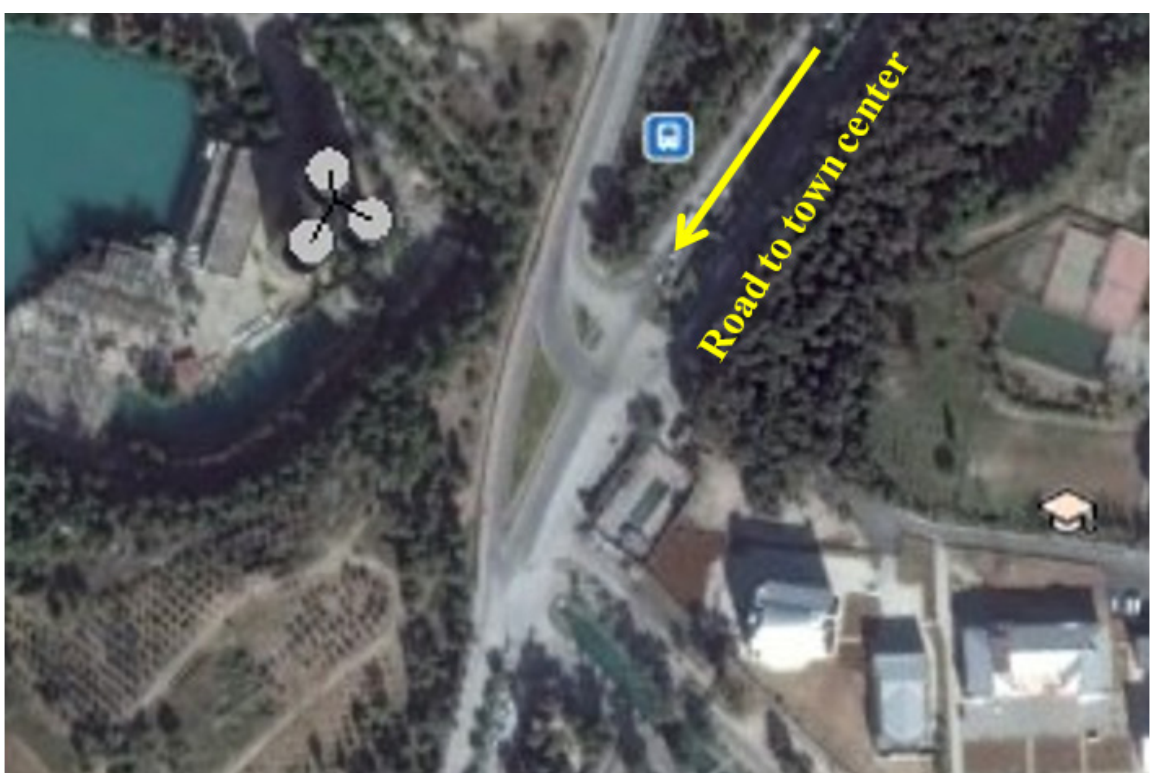

Figure 1:Satellite image of modelled intersection which combines ÇU campus to town center

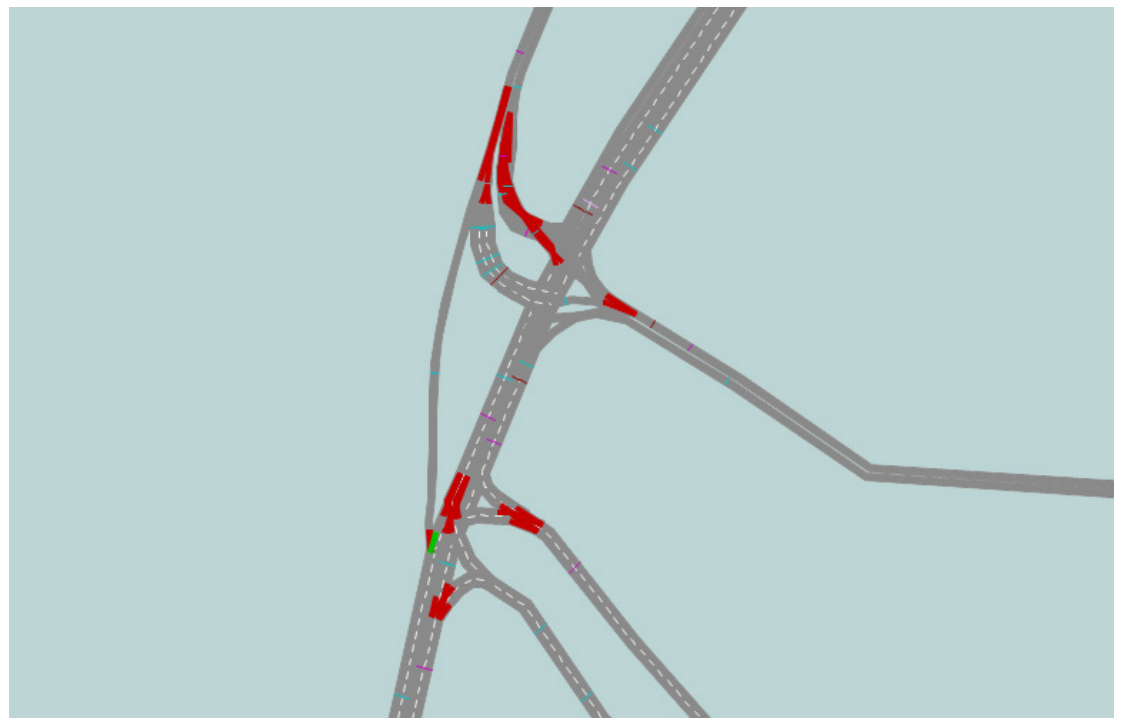

Figure 2. Screen shot of VISSIM simulation model

The main aim of signal timing optimization involves decreasing queue lengths and delays at that intersection. For the simulation of the intersection, VISSIM software is selected. In order to check the simulation results; field delay values were compared with the simulated delay values. The acceptable limit of deviation of field data and simulated delay values is $15 \%$.

In order to simulate a traffic situation and get the desired output, some input field data has to be entered to the VISSIM software, such as geometries of connectors and links, actual signalization timings and route decisions of vehicles. By the use of that information, software can compute vehicle travel times and queue lengths formed at selected ways. Some inputs necessary for simulation and outputs of the VISSIM software are shown in Table 1.

Table 1 Some input and input values used in VISSIM

\begin{tabular}{|c|c|}
\hline Inputs & Outputs \\
\hline Geometries of links and connectors & Queue length \\
\hline Percentage of vehicles choosing a route & Delay \\
\hline Signalization timings & Travel Time \\
\hline Vehicle compositions & Emission Gases Formed \\
\hline Priority rules of the roads & Fuel Consumption \\
\hline
\end{tabular}




\section{RESULTS AND DISCUSSION}

Signal period of the simulated intersection takes $85 \mathrm{sec}$, which is composed of green time of $30 \mathrm{sec}$, red time of $52 \mathrm{sec}$ and amber of $3 \mathrm{sec}$. Default vehicle compositions of VISSIM were used in this study; vehicle volumes were estimated according to data of number of candidates and instructors entering central exams.

Time period of 16 minutes after end of the exam exit was selected for the analysis. Travel times that are obtained from the field were compared with data obtained from simulation in order to validate the output of VISSIM software. Travel times within different time intervals for $30 \mathrm{sec}$ green time is shown Table 2. Travel time taken from the field for 2 minutes after exam exit is $85 \mathrm{sec}$ for that interval which deviates around $8.81 \%$ from the simulation values.

Table 2 Variation of travel time values after exam exits obtained from simulation.

\begin{tabular}{|c|c|}
\hline Time Interval & Travel Time (Sec) \\
\hline $12: 00-12: 02$ & 40,1 \\
\hline $12: 02-12: 04$ & 93,21 \\
\hline $12: 04-12: 06$ & 109,69 \\
\hline $12: 06-12: 08$ & 161,54 \\
\hline $12: 08-12: 10$ & 195,3 \\
\hline $12: 10-12: 12$ & 230,46 \\
\hline $12: 12-12: 14$ & 282,72 \\
\hline $12: 14-12: 16$ & 342,94 \\
\hline
\end{tabular}

The variation of travel time for different green times is shown in Figure 3. Travel times reduced with the increased green times (There is an average of about $25,9 \%$ reduction for $38 \mathrm{sec}$ green time compared to $30 \mathrm{Sec}$ ). The value of travel time reduction amount is higher at later stages than that of at earlier periods.

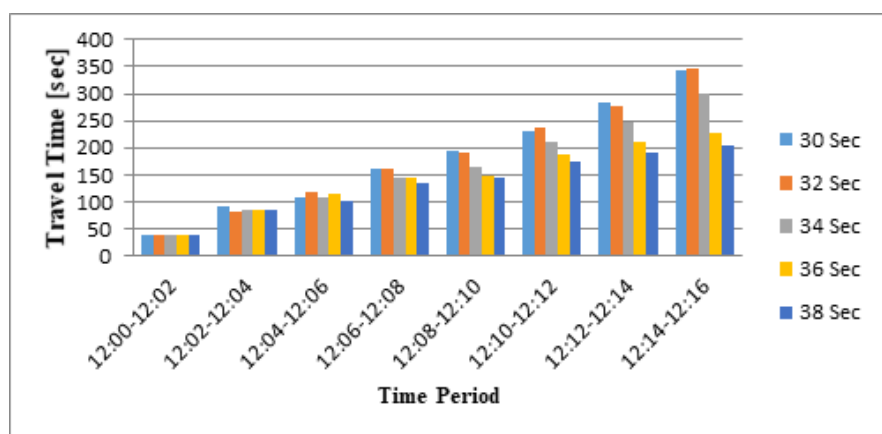

Figure 3:Variation of travel time values for different green times within 2 minutes of time periods

The variation of queue length values for different green time periods is presented in Figure 4 . On an average a $23.3 \%$ reduction in queue lengths is obtained for $38 \mathrm{sec}$ green length compared to $30 \mathrm{sec}$ green length.

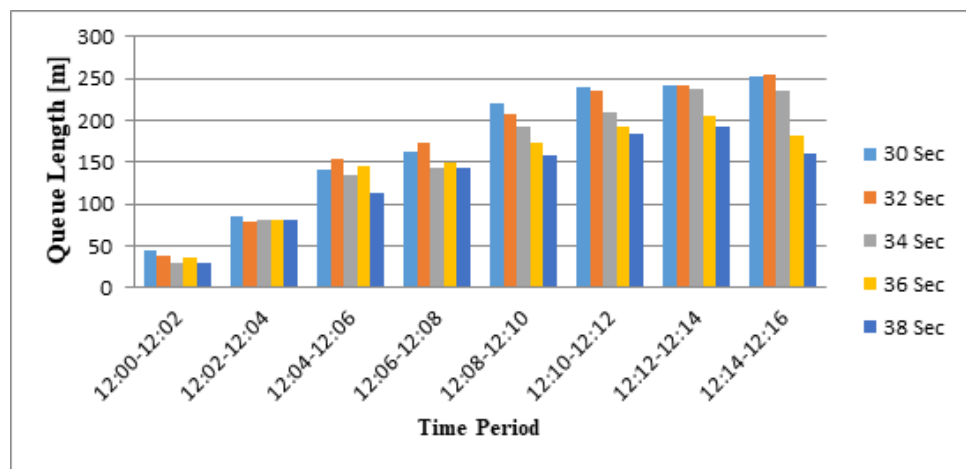

Figure 4. Variation of queue lenghts for different green times within 2 minutes of time periods

$\mathrm{CO}_{2}$ emission is produced by complete combustion of fuel [12,13]. Figure 5 demonstrates the variation of calculated $\mathrm{CO}_{2}$ emission values for different green time values. There is an average of $14,4 \%$ reduction in total $\mathrm{CO}_{2}$ emission values when $38 \mathrm{sec}$ green time is used instead of $30 \mathrm{sec}$. 


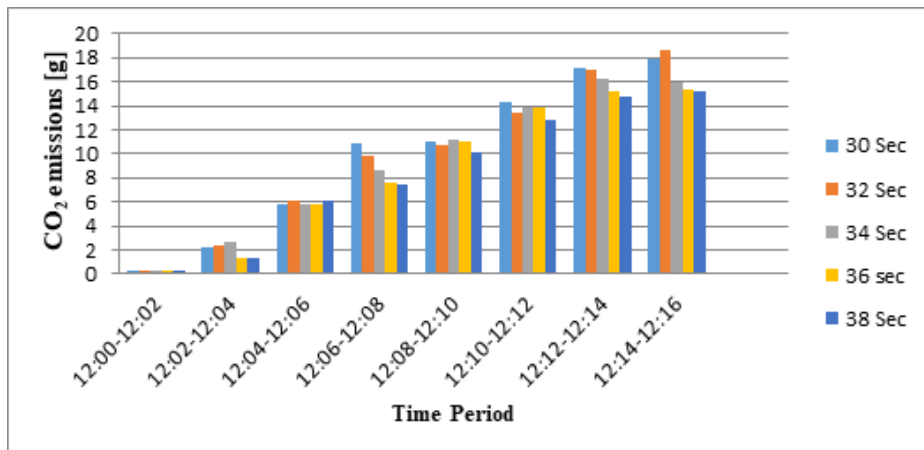

Figure 5. Variation of total CO2 emissions for different green times within 2 minutes of time periods

\section{CONCLUSIONS}

The campus traffic after central exams in Çukurova University was simulated in order to optimize signalization timing at the intersection of campus exit. The simulation results showed that change in green times has a significant effect on vehicle travel time, queue length and vehicular emissions. The traffic signals are advised to be arranged that they provide more green time after central exams for vehicles try to exit from the Çukurova University campus. Increase in green time after exams will also reduce loss of time and harmful emissions from vehicles in traffic.

\section{REFERENCES}

[1] Bambode, K., Gajghate, V., (2014). Traffic Signal Optimization for Important Routes In Nagpur City: A Review. International Journal of Emerging Technology and Advanced Engineering, vol. 2 no. 4, pp.511-514.

[2] Stevanovic A., Stevanovic J., Zhang K., and Batterman, S., (2009). Optimizing Traffic Control to Reduce Fuel Consumption and Vehicular Emissions. Transportation Research Record; pp.105-113.

[3] Sumeet K., Ketankumar V., (2015) "Use of Vissim in Heterogeneous Traffic Modelling-A Review. Indian Journal of Research, vol. 5 4., pp. 453-454.

[4] Hallmark, S. L., and R. Guensler. (1999). Comparison of Speed and Acceleration Profiles from Field Data with NETSIM Output for Modal Air Quality Analysis of Signalized Intersections. In Transportation Research Record: Journal of the Transportation Research Board, No. 1664, TRB, National Research Council, Washington, pp. 40-46.

[5] Rouphail, N. M., Frey C. H., Colyar J. D., and Unal A.,(2001). Vehicle Emissions and Traffic Measures: Exploratory Analysis of Field Observations at Signalized Arterials. Presented at 80th Annual Meeting of the Transportation Research Board, Washington, D.C.

[6] Marsden, G., M. Bell, and S. Reynolds.(2001). Towards a Real-Time Microscopic Emission Model. Transportation Research, vol. 6; pp. 37-60.

[7] Rakha, H. A., and Y. Ding. (2001). Impact of Vehicle Stops on Vehicle Energy and Emissions. Presented at 80th Annual Meeting of the Transportation Research Board, Washington, D.C.

[8] Robertson, D. I., C. F. Lucas, and R. T. Baker., (1980). Coordinating Traffic Signalsto Reduce Fuel Consumption. TRL Report LR934. TransportResearch Laboratory, Crowthorne, Berkshire, United Kingdom.

[9] Dissanayake D.T, Senanayake S.M.R, Divarathne H.K.D., Samaranayake B.G.L.T. (2009). Real-Time Dynamic Traffic Light Timing Adaptation Algorithm and Simulation Software

[10] PTV.VISSIM 5.40-03 User Manual. PTV Planung Transport Verkehr AG, Karlsruhe, 2012.

[11] Karthik G., Ralegoankar R.V.(2014). Optimization of signal timings at signalized intersections in Indian Scenario. Transportation Planning and Implementation Methodologies for Developing Countries.

[12] Uludamar, E. et al. (2017). Evaluation of vibration characteristics of a hydroxyl (HHO) gas generator installed diesel engine fuelled with different diesel-biodiesel blends. International Journal of Hydrogen Energy, https://doi.org/10.1016/j.ijhydene.2017.01.192

[13] Yıldızhan, Ş., Uludamar, E., Çalık, A., Dede, G. , Ozcanlı, M.(2017). Fuel properties, performance and emission characterization of waste cooking oil (WCO) in a variable compression ratio (VCR) diesel engine. European Mechanical Science, vol. $1(2)$, pp. 56-62 